\title{
Improving Graduate Futures and Employability Through Embedded Industrial Experience
}

\section{Dr John Dixon* \& Dr Neil Gordon}

Department of Computer Science and Technology, University of Hull, Hull,HU6 7RX, U.K

${ }^{*}$ Corresponding Author: john.dixon@hull.ac.uk

Keywords: Computer Science; Computing; Curriculum Development; Education; Employability; Employment; Industrial Experience

\begin{abstract}
The financial cost to individuals of higher education is now regularly exceeding $£ 50 \mathrm{k}$ before maintenance in the UK; consequently, students are more concerned than ever that their degree should offer value for money when they enter the jobs marketplace. Overshadowed by long-term debt, lack of career options and job offerings with low salary, student numbers in the arts, languages, humanities and philosophy areas have suffered compared to most STEM disciplines (Universities UK, 2018). Computer science, I.T. and computing tend to buck this trend (HESA, 2020), and, with a drive toward reskilling the workforce for a more technologyfocussed future, this suits Government strategy. However, graduate employers want to hire individuals who are well rounded and have experience; businesses identify that more general workplace experience is key.
\end{abstract}

The subsequent sections describe a level 7 (Master's) capstone project module, Commercial Development Practice, dedicated to fulfilling these employer requirements by focussing on project processes rather than project products. The practicalities of running this module and considerations that have been key for the successful application of this technique over the 14 years the module has been running are discussed. The curriculum, pedagogic approaches and assessment methods are presented.
The evaluation of this approach, which analyses the impact and student experience and perception of the module using data gathered since 2015, has found that participants gain valuable skills, experience and confidence which leads to more employable graduates.

\section{Introduction}

A challenge for higher education providers is how to offer students real-life learning experiences, which promote commercially relevant expertise. A further issue is the student perception of such approaches.

The work-experience trap (Pastore, 2017) is a commonly cited drawback to a lengthy stay in education. Computer science has a particular challenge with employability, because real-life practice is potentially side-lined or ignored in favour of "toy problems" (Fincher \& Finlay, 2016), with easily marked coursework and assessments which encourage fact regurgitation in limited areas. Even in educational projects with a larger scope, STEM studies may focus on scientific practice and teacher-centred learning - offering reward for academic writing and individual scholarship which is not often common or valuable in the workplace (Connor et al., 2015).

There are, however, well established methods for promoting real-life learning experiences: 
- Through team working and industryfocused or industry led input into programme modules and assessment,

- With individual placements in industrial settings; e.g. summer or year-long internship,

- Authentic assessment that is based around activities that mirror practice,

- Or through student projects (usually individual) which focus on producing a 'realistic' output; e.g. dissertation projects.

Methods by which higher education institutions seek industrial advisory input for course or module content (e.g. Forshaw et al., 2016) are, rightly, considered best practice, and outcomes tend to favour project-based learning in groups. These activities offer opportunities for students to develop the soft, industry-relevant skills that employers say are important. However, many institutions find that it is difficult to offer students a realistic commercial environment outside of the constraints of a commercial setting or where dedicated resources are unavailable (Wilde et al., 2003). Due to the need for consistent assessment and, sometimes, high numbers of students involved, computing projects may be superficial, have no real-world importance and may be common across a large cohort. Various drawbacks to project-based group work have been identified (Joyce \& Elliot, 2007). Since, for example, work is commonly completed outside contact time, measuring engagement is difficult and students may avoid working together or avoid working altogether. Student perception of participating in and being assessed through group work therefore tends to be poor, and fair assessment is difficult. There are mechanisms to mitigate against the worst effects of this, such as peer assessment tools (Gordon, 2010) and regular check-up sessions, but the outcomes are less than ideal (Ashworth et al., 1997) with employers still calling for improved skills (Riebe et al, 2016).

There is clear evidence that industrial placements are valuable to both students and the associated organisation (Patel et al., 2012). Student employability is greatly improved through experiencing a commercial environment with professional expectations whilst still having the opportunity to make mistakes without fear of the repercussions that may befall a salaried employee. Invariably, students excel in time management and professional skills when coming back into education, giving them a great advantage in their studies. Often, these students return more certain about their future career trajectory and regularly have job offers on the table. However, promoting these options in a climate of rising tuition fees is a challenge, where students would prefer to start earning after three years or improve their employability through a Masters level qualification instead (Thompson et al., 2005).

Unfortunately, with only $14 \%$ of computer science Masters level candidates going into jobs which have a formal requirement of postgraduate study (HESA, 2017), level 7 qualifications do not necessarily offer higher employability or command a larger salary on their own. Therefore, to provide real value to students and employers alike, educational institutions must combine opportunities for continued study and in-depth subject knowledge with functional, employabilityboosting real-world experience.

Student dissertation projects can be made commercially relevant through close business or research partnership but, in the context of employability, integrating real-life experiences which help close the experience gap is difficult. This tends to be because capstone projects are necessarily individual in nature, primarily to aid assessment of technical competence without peer influence (Hribar, 2005). It is also the case that examination of undergraduate dissertation projects in STEM subjects tends to focus on a solution to a problem and a scientific write-up rather than key professional skills. This, arguably, is reasonable. We should provide students an opportunity to enhance and showcase subject-specific skills which have been developed over the course of their studies, and we should expect a standard of scientific discipline from university graduates.

For a Masters qualification, however, we can expect that students have already completed a dissertation at level 6 which focusses on independent study and assesses technical competence. Reassigning a similar, but more in-depth project at level 7 may be the right 
option for students who are focussed on academic or scientific advancement, but many computer scientists do not go into scientific jobs. For those who want a Masters qualification which also enhances their employability, a conventional dissertation may not be the best option.

At the University of Hull, the Department of Computer Science and Technology established a MEng course, offering a capstone 40 credit module which runs across the year, focussing on giving students realworld, commercial experience. This capstone Commercial Development Practice (CDP) module gives all the students on the degree the opportunity to gain invaluable practice, working together in planning, designing, creating and testing real, production-ready software for real clients whilst managing their projects using industry-standard Agile methodologies.

Unlike the conventional MSc model of three trimesters, where one is dedicated to a dissertation, the MEng is an integrated Masters, so is completed in two trimesters and offers graduation in the summer.

\section{Module Justification}

It is important to first examine the expected capabilities and skills that students should exhibit according to external influencers such as the Quality Assurance Agency (QAA), the programme accreditor - the British Computer Society (BCS), and employers, then to compare these with module learning outcomes and curriculum design.

QAA benchmarking statements for Computing (QAA, 2019a) focus on technical knowledge, and then competencies such as:

- Understanding legal, social, ethical and professional issues (LSEPI)

- Demonstrating entrepreneurship and innovation

- Working effectively in a team, and demonstrating leadership, communication and translational skills (non-technical audiences)

- Underpinning principles of quality, design and methodology

- Ready for professional practice, reflective practice, critical evaluation and lifelong-learning skills (e.g. goalsetting)

Similarly, the BCS specify comparable accreditation requirements for Chartered IT Professional (CITP) status at the Master's level (BCS, 2020). Perhaps unsurprisingly, these competencies are extremely prominent in the Computing Master's level benchmarking statements (QAA, 2019b), where all of the threshold level expectations include professional practice. This highlights a serious issue with the student perception of a Computer Science degree, which tends to anticipate that subject-specific skills are valued above transferable skills, causing employer headaches (Radermacher et al., 2014). In reality, competence in subject-specific skills is expected at BSc level, and Masters level students are expected to have additionally developed professional and interpersonal proficiencies.

Surveys and research focussing on graduate employers shows that they want to hire individuals with communication, problem solving and team working skills, who are also contemplative, reflective and creative - see (Hamilton et al., 2015), (Kranov \& Khalaf, 2016) and (Prinsley \& Baranyai, 2013). The current convergence and concentration of students away from naturally creative and reflective subjects towards few, relatively similar STEM focussed courses risks diminishing the range of skills present in the overall workforce and an oversaturation of similar ideologies. Therefore, it is more important than ever that learning activities challenge and encourage graduates to build general, soft skills which complement the core course aims, producing more well-rounded prospective employees with a range of secondary expertise.

The learning outcomes for this module cover elements associated with these key competencies: commercial and economic perspectives of software development, project management and methodologies, teamwork, use of contemporary tools, critical evaluation, self-direction and self-led learning, innovative solution development, professionalism and planning. These objectives cover the gamut of intellectual, practical and transferrable skills. However, the curriculum was developed 
mindful of the fact that subject-specific technical skills required, which are not directly covered (although may be practiced) in this module, are covered elsewhere in the programme.

\section{Replicating the Approach}

The module is organised around a central group project. These projects are real, and specified by clients who are external third parties.

In order to replicate and maximise the benefit of this opportunity, certain project parameters are essential:

- The work should be relevant to the subject discipline, but the focus should be on experiences valued by employers,

- Real clients and real projects, with commercial relevance and consequence, are essential for both genuine experience and student engagement,

- Clients should be available and involved with the projects and be seeking an output with real commercial value,

- The projects or part-projects should be small enough in nature to ensure that students have enough time for other Masters level academic study,

- Work should be completed in teams but with dedicated work days, an office environment and real project management methodologies,

- Projects should span a range of industries and areas of expertise to ensure practical experience is still in keeping with student interests,

- Students should be trusted as employees and given opportunities to develop self-led learning techniques which are key to lifelong learning in the workplace,

- Academic input should not interfere with the work, and assessment should focus on the processes and practices used by individuals and teams (the experience employers want to see) rather than the project completion or solution code,
- Assessment should be separate from teamwork, allowing a focus on the project during working hours and providing an opportunity for marks to be allocated independently,

- Students should be supervised, and support offered, but they should not be directly managed or instructed, allowing development of initiative and independence.

As a fundamental activity then, the project offers a hub from which the learning outcomes can be addressed and assessed. The module assessment focusses on the processes and practices employed to accomplish the project, not on the actual completion of the project itself. The opportunity to practice software development skills and the commercial outcome are by-products of successfully engaging with the core learning objectives of the module. However, the involvement of a real client and the fact that the software needs to be production-ready concentrates and energises the team to produce a high-quality solution.

When considering the module in context, both as part of the larger four-year integrated Masters and as part of the level 7 year of study, it is important to identify that students have both a large body of taught knowledge underpinning their decisions, and that they are provided with further subject-specific teaching as part of the fourth year. This module therefore assumes that students already have a strong BSc-level knowledge of the core technologies and processes and ensures that the participants can move quickly into project work to make progress and develop through practice and application.

The working portion of the project is conducted in a commercial environment, with teams (3-5 students per project) co-located at permanent desks in a dedicated office space. The room replicates the conditions of an industrial environment during the allocated hours. Students work 9 am to $5 \mathrm{pm}$ for 40 days over the course of the academic year - usually on Mondays only, but with some full-time weeks spread across the trimesters.

Due to the placement-like nature of this project, students are encouraged to work only during specified working hours and to not take project 
work home or work overtime. These provisions mirror real working conditions and help mitigate against issues experienced in conventional academic group-work which tend to undermine the experience (e.g. coasting, disengagement, separate working, procrastination, etc.).

In order to maximise the time available to work on the project, the lectures and taught material is front-loaded into a week-long intensive period. For the most part this is signposting, and transitions quickly to an active learnercentred pedagogy, specifically, project-based learning. To smooth this transition, students are given teacher-specified inquiry-based learning tasks during the first week. This is effective in laying a foundation of core knowledge, empowering students through effective constructive alignment (Biggs, 1996). Core knowledge includes the teaching of project management methodologies which focus on analysis, synthesis and evaluationbased approaches towards improving working practices, pushing students to engage with the higher-order thinking skills (Bloom, 1956) expected at level 7.

However, learning, even in employment, is not a wholly self-led exercise, and without input it can be hard to know what to focus on. An external manager is brought in from industry, not to manage the projects per se but to offer guidance and support. Industry professionals are also invited to speak and share best practice outside of office hours - thus not interfering with the project work but offering avenues for practical learning similar to opportunities available in the workplace.

\section{Assessment}

To accommodate learning, assessment is individual and primarily takes place after the project has been finished. Summative assessment is managed through a personal reflective portfolio of evidence and an individual viva voce. The portfolio is to be completed outside of working hours and comprises evidence that is routinely created by engaging with the module activities, along with reflections on this evidence and a critical evaluation of personal contributions and skill development. Due to this back-loading, assessment is lightweight and not a constant, overbearing facet of this module so focus can be retained on the core learning objectives and experiences. This addresses common educational concerns over over-assessment (Sambell, Brown \& Race, 2019). These elements, together, make up the vast majority of the marks available and, due to the individual nature of the assessment, mitigate against any possibility of bloated marks due to coasting and unbalanced contribution often found in group work.

Assessment also includes observation of progress and participation (which is possible due to the fact that the work is completed under supervision), and peer assessment (which enables students to assess one another to help balance marks fairly according to contribution and highlight previously unseen team dynamics).

Formative feedback is core, as part of the process. However, the students are expected and encouraged to seek this out for the most part. This includes interaction with the managers (academic and industrial) and clients. All stakeholders are interested in the successful implementation of a solution so this feedback is useful and relevant to the project continuation. However, structured formative assessment (presentation of work and guided discussion) are applied regularly throughout the process to engage and empower new avenues of exploration, and to mirror more formal workplace reporting processes. Students report that they particularly value the opportunity to ask questions of a member of staff who is not also responsible for examining them (external manager) - this eases feelings of the need to perform for academic purposes. At the end of the process, teams participate in an MEng Graduate Exhibition where they present their project, its outcomes and their achievements to invited leaders from the software development industry who ask questions and provide formative feedback from the perspective of both employer and expert. This event offers students the ability to share their work in a formal setting and provides an additional incentive to meet industrial expectations through the knowledge that this awaits them at the end of the year. 
Improving Graduate Futures and Employability Through Embedded Industrial Experience

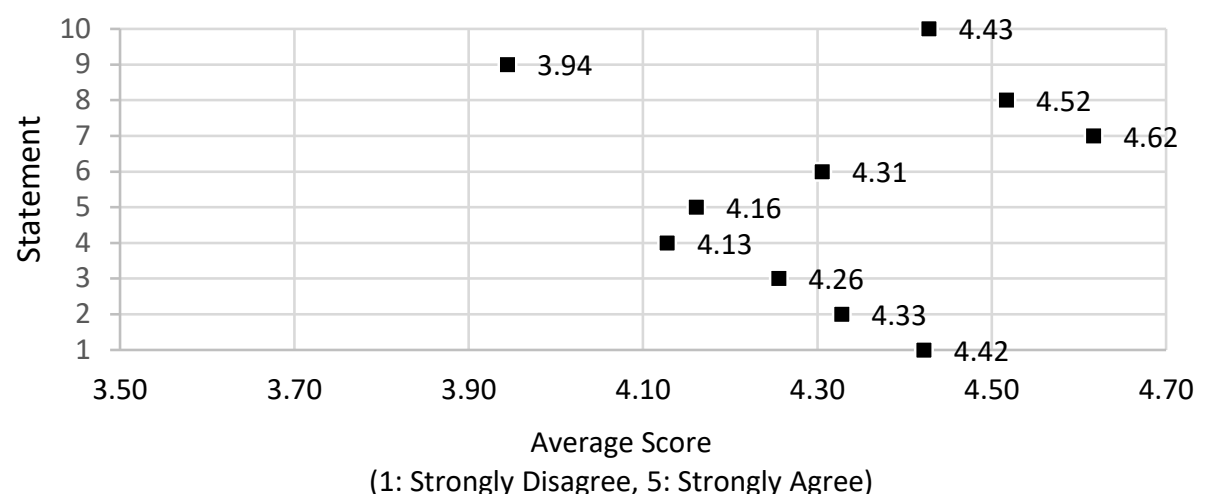

Figure 1 Comparison of Section 1 Average rating across all Statements (see table 1 for statement questions).

\section{Evaluative Methodology}

To evaluate this approach a standardised student survey has been conducted since 2015. This comprises a feedback form dedicated to the module, covering objectivespecific outcomes from the student perspective. The questionnaire is given to the students after the end of their project but before marks are awarded, avoiding contamination from elation or dejection resulting from academic grading and instead allowing students to focus on the experience gained. Students are asked to answer objectively, whether or not they enjoyed the experience.

Students participated in this study voluntarily and the response rate was $>75 \%$, although perceptions of students who did not complete their programme could not be collected. These students report leaving for a variety of reasons, including employment elsewhere, health complications and poor academic performance in other Masters modules. In all cases early leavers were asked to indicate if their experiences in CDP had been poor or had contributed to their decision. All respondents identified that this was not the case.

The survey is broken down into three sections:

1) Ten, five-point Likert scale statements, asking students to indicate if they feel their experience has improved their abilities across the learning objectives (strongly disagree to strongly agree) [figure1, table 1],

2) Nine pre/post elements, asking students to rate their relevant skills and abilities at the start and end of the year (scale from 1-10, where 1 is weakest and 10 is strongest) [table 2], and
3) Four direct yes/no statements, identifying overall satisfaction with the module [table 3].

There is also the opportunity for students to provide freeform elaborations on their perception of personal improvement due to CDP.

\section{Findings}

The findings show data averaged from all data available (surveys conducted 2015-2019, 50 student respondents).

Each of the three sections presented in the Evaluative Methodology, above, are shown alongside the statements and elements that the students were asked to consider.

Many students noted, in elaboration, that their responses, especially 3 and 4 , were lower due to their having experienced these elements before (e.g. in past jobs).

A number of students identified that the process was extremely valuable in boosting confidence, improving key skills and offering the ability to be part of a community in an environment where all participants are committed.

Few students provided negative elaborations where these did exist the comments were focussed on issues surrounding team breakdown and the significance to their degree programme (e.g. students taking a 'Computer Science for Games' programme who wanted to be allocated a project more focused on producing a video game). 
Improving Graduate Futures and Employability Through Embedded Industrial Experience

\begin{tabular}{|c|c|c|c|c|c|c|}
\hline Statement & 5 & 4 & 3 & 2 & 1 & $\begin{array}{l}\text { Average } \\
\text { rating }\end{array}$ \\
\hline $\begin{array}{l}\text { 1. My experience in CDP has improved my } \\
\text { employability }\end{array}$ & 53.2 & 42.6 & 2.1 & 0 & 2.1 & 4.42 \\
\hline $\begin{array}{l}\text { 2. My experience in CDP has improved my } \\
\text { technical skills (programming, using new } \\
\text { software/ides/apks, etc.) }\end{array}$ & 42.6 & 48.9 & 4.3 & 4.3 & 0 & 4.33 \\
\hline $\begin{array}{l}\text { 3. My experience in CDP has improved my team- } \\
\text { working skills }\end{array}$ & 38.3 & 48.9 & 10.6 & 2.1 & 0 & 4.26 \\
\hline $\begin{array}{l}\text { 4. My experience in CDP has improved my } \\
\text { organisational skills }\end{array}$ & 27.7 & 59.6 & 10.6 & 2.1 & 0 & 4.13 \\
\hline $\begin{array}{l}\text { 5. My experience in CDP has improved my software } \\
\text { development skills (version control, quality, } \\
\text { testing, etc.) }\end{array}$ & 34 & 53.2 & 8.5 & 4.3 & 0 & 4.16 \\
\hline $\begin{array}{l}\text { 6. My experience in CDP has improved my } \\
\text { understanding of how software developers work }\end{array}$ & 40.4 & 51.1 & 8.5 & 0 & 0 & 4.31 \\
\hline $\begin{array}{l}\text { 7. My experience in CDP has improved my ability to } \\
\text { work with real clients }\end{array}$ & 63.8 & 31.9 & 4.3 & 0 & 0 & 4.62 \\
\hline $\begin{array}{l}\text { 8. My experience in CDP has improved my } \\
\text { understanding of software development } \\
\text { methodologies (e.g. Scrum) }\end{array}$ & 55.3 & 40.4 & 4.3 & 0 & 0 & 4.52 \\
\hline $\begin{array}{l}\text { 9. My experience in CDP has improved my ability to } \\
\text { write useful documentation }\end{array}$ & 12.8 & 68.1 & 19.1 & 0 & 0 & 3.94 \\
\hline 10. I have improved due to my experience in CDP & 48.9 & 46.8 & 2.1 & 2.1 & 0 & 4.43 \\
\hline
\end{tabular}

Table 1 (Section 1: Likert) Likert scale where 1 is strongly disagree and 5 is strongly agree, the percentage number of students choosing each rating for each statement in Section

\begin{tabular}{|c|c|c|c|c|c|}
\hline Statement & $\begin{array}{c}\text { Mean } \\
\% \\
\text { Change }\end{array}$ & $\begin{array}{c}\text { Max } \\
\% \\
\text { Change }\end{array}$ & $\begin{array}{c}\text { Min } \\
\% \\
\text { Change }\end{array}$ & LQ \% & UQ \% \\
\hline 1. My technical skills at the start/end of the year & 22.5 & 55.56 & 0.00 & 12.96 & 25.93 \\
\hline $\begin{array}{l}\text { 2. My team-working skills at the start/end of the } \\
\text { year }\end{array}$ & 26.0 & 66.67 & 0.00 & 13.89 & 35.19 \\
\hline 3. My management skills at the start/end of the year & 28.4 & 88.89 & 0.00 & 14.81 & 39.81 \\
\hline $\begin{array}{l}\text { 4. My software development skills at the start/end } \\
\text { of the year }\end{array}$ & 26.1 & 66.67 & 0.00 & 17.59 & 29.63 \\
\hline $\begin{array}{l}\text { 5. My ability to work with real clients at the start/end } \\
\text { of the year }\end{array}$ & 49.0 & 88.89 & 0.00 & 31.48 & 66.67 \\
\hline $\begin{array}{l}\text { 6. My understanding of software development } \\
\text { methodologies at the start/end of the year }\end{array}$ & 41.7 & 77.78 & 0.00 & 29.63 & 50.93 \\
\hline $\begin{array}{l}\text { 7. My ability to write useful documentation at the } \\
\text { start/end of the year }\end{array}$ & 29.1 & 100.00 & 0.00 & 11.11 & 40.74 \\
\hline 8. My professionalism at the start/end of the year & 17.1 & 77.78 & 0.00 & 3.70 & 25.00 \\
\hline $\begin{array}{l}\text { 9. My overall computer science skills \& ability at the } \\
\text { start/end of the year }\end{array}$ & 21.8 & 55.56 & 11.11 & 11.11 & 25.00 \\
\hline
\end{tabular}

Table 2 (Section 2: Scale Rating Change (1-10)) Comparison of change for before/after values for scale rating elements in Section 2 where a positive $\%$ indicates a positive change perceived by the student(s) 
Improving Graduate Futures and Employability Through Embedded Industrial Experience

\begin{tabular}{|c|c|c|}
\hline Statement & Yes & No \\
\hline 1. Work experience like CDP is a useful part of a university education & $93.33 \%$ & $6.67 \%$ \\
\hline 2. I feel more equipped to get a job than I did a year ago & $95.00 \%$ & $5.00 \%$ \\
\hline $\begin{array}{l}\text { 3. CDP has helped me to gain experience in the entire process of developing } \\
\text { software }\end{array}$ & $95.56 \%$ & $4.44 \%$ \\
\hline 4. I am more confident in what I want to do next, because of CDP & $76.11 \%$ & $23.89 \%$ \\
\hline
\end{tabular}

Table 3 (Section 3: Yes/No Questions) Percentage of students answering each statement as Yes or No in Section 3

\section{Discussion}

The CDP offering has seen extremely high approval from students, with many returning to thank the staff involved after securing jobs or having started work. Often these students underline the value in providing experience that can be discussed in interview and the additional confidence that they felt applying for and starting employment.

There are still difficulties which must be overcome. Many times students fall into the trap of diving headfirst into programming with little attention to planning tasks, quality-first considerations or following an Agile methodology. This is regularly recognised, by both students and staff, as a result of an education where the focus is skewed towards assessing project output rather than the entire project lifecycle. Students are used to producing code fast, through a messy trial-anderror approach which is good for learning, prototyping and submitting coursework on time but not good for production software. This can result in a thin veneer of methodology being applied for the sake of marks rather than to underpin the work. Often this is rectified once formative and early feedback is given but occasionally students are unwilling to gravitate to seeing processes and practices as important elements of a successful project, preferring instead to focus on technical achievement at all costs.

Staff also find that students are often wary of asking for help, feeling that to do so could indicate that they are incapable. At the outset participants are informed that they will feel "thrown in at the deep end" due to the large task of managing a real software project for the first time. As indicated, staff are supervisory not directly managerial but students are prompted to ask for help and discuss any problems. The reluctance seems to stem from an educational norm where pupils are either spoon-fed everything they need to know or feel that asking questions shows ignorance. This is particularly challenging given that part of the module aims to promote independence occasionally, students fail to realise that independent learning in the workplace includes the ability to know what you do not understand and seek out betterment, which may often include asking for help.

It is also difficult to find a range of projects to suit all tastes. This requires keeping a pool of projects that are larger than the number that could be achieved in a year and seeking clients from a range of industries. It is particularly difficult to find game-based projects for students on game development programmes as there are not often clients with requirements for these outputs. Many students, however, appreciate that, no matter what project they work on, their employability is boosted through the experience gained.

Student survey responses provide an insight into the module success and indicate high approval across all sections.

In section 1, responses reveal a high agreement $(>4)$ on average for all statements except statement 9 ("My experience in CDP has improved my ability to write useful documentation") which scores marginally below 4. This is attributed to the Agile manifesto value specifying "Working software over comprehensive documentation" and has since been combatted with additional focus on the PRINCE2 project management methodology alongside Agile.

Section 2 responses show significant improvements are expected across all 9 elements, with particularly high improvement in ability noted in working with real clients and 
software development methodologies. The only element below an average 20\% improvement is professionalism. Many students rated themselves highly for this at both the start and end of the year, with little room for improvement. It is interesting to consider the motivations and factors underpinning this confidence, but important to acknowledge that students had different baselines for these metrics so it is only appropriate to scrutinise overall perceptions of improvement.

Section 3 indicates a high level of satisfaction and feeling that the module adds value. This is significant because, unlike the majority of education, this process asks students to focus on the process rather than the output and offers the opportunity to develop skills by undertaking a project that is not well defined at the outset. These elements are heavily discussed in the free text comments attached to section 1.10 ("I have improved due to my experience in CDP") where students often described their increased confidence and ability to selectively improve skills that were important to them.

Comparing the outcomes of this module to other similar opportunities help to corroborate these findings. Glasgow Caledonian University's Integrated Project module is an opportunity for students to develop commercial skills in their first year (McKinnon and McCrae, 2012). This pilot showed some impression of boosted employability, but included few mechanisms to replicate the workplace, likely due to the difficulties in offering realism to a larger cohort. Unlike CDP, the findings indicated that students felt less confident in their technical ability at the end of the project, which is attributed to the fact that these are first year students who have not yet learned the technical skills required to complete the work. It is evident that application of prior knowledge is key, and also worth considering that commercial practice may not be relevant to all undergraduates.

The University of Sunderland has experimented with offering real life learning experiences at Masters level, providing clients and academic support (Thompson et al., 2005). However, the opportunities afforded through this capstone project appear limited, with stilted client interaction, no formal working environment and no clear team-working element - offering minimal real-world experience beyond a conventional MSc dissertation. It seems that the intent is to run these projects on a much larger scale (500-600 students) making it infeasible to offer the same level of realism and resulting in many difficulties for the academic staff. There are, however, some clear similarities, especially with regard to assessment, identifying common practice across modules with similar aims.

Given the focus on improving employability it would be valuable to collect feedback from employers about the value of the module. However, it is difficult to achieve this without straying into the hypothetical, or approaching companies who employ our graduates for feedback on the quality of the employee which is infeasible. We do involve industry however, especially in the Graduate Exhibition, where informal feedback has praised the high value of this approach. Client feedback has also been very good, with clear indication that clients feel the process is useful for all stakeholders. The 'Destinations of Leavers' data from 2016 and 2017 shows a 26\% higher employment rate for MEng students over BSc students, with $84 \%$ of MEng students securing a job of graduate-level or higher after leaving.

\section{Conclusion}

It is possible, and increasingly necessary, to offer graduates real-life learning experiences which promote commercially relevant expertise, and there are a number of methods to do this.

The CDP approach appropriately matches the QAA and BCS requirements and benchmarks applicable to this level, offering balanced learning opportunities facilitated by real application. The assessment methods are designed to be lightweight, minimising impact from over assessment and allowing students to develop professional skills and engage in project-based learning. Typical apprehensions over this pedagogy are mitigated against to ensure contribution is balanced and assessment is individualised.

It is clear from the student responses and accompanying data that this approach is 
Improving Graduate Futures and Employability Through Embedded Industrial Experience

enhancing skills and understanding and providing significant improvement across all key module objectives. Students overwhelmingly feel more equipped to get a job, more confident in what they want to do next and affirm that that this type of offering should be a part of a university education.

\section{References}

Ashworth, P., Bannister, P., Thorne, P. \& Unit, S. O. T. Q. R. M. C. (1997). Guilty in whose eyes? University students' perceptions of cheating and plagiarism in academic work and assessment. Studies in higher education, 22, 187-203. DOI:

\section{$10.1080 / 03075079712331381034$}

\section{BCS (2020). Guidelines on Course}

Accreditation. Available online:

https://www.bcs.org/media/1209/accreditationguidelines.pdf [Accessed 25/04/21]

Biggs, J. (1996). Enhancing teaching through constructive alignment. Higher education, 32, 347-364. DOI: 10.1007/BF00138871

Bloom, B.S. (1956). Taxonomy of educational objectives. Vol. 1: Cognitive domain. New York: McKay, 20-24.

Connor, A., Karmokar, S. \& Whittington, C. (2015). From STEM to STEAM: Strategies for enhancing engineering \& technology education. International Journal of Engineering Pedagogy, 5, 37-47. DOI: 10.3991/IJEP.V5I2.4458

Fincher, S. \& Finlay, J. (2016). Computing graduate employability: sharing practice. Project report. Council of Professors and Heads of Computing, Kent, UK. Available online: https://kar.kent.ac.uk/53848/

Forshaw, M., Solaiman, E., McGee, O., Firth, H., Robinson, P. \& Emerson, R. (2016). Meeting Graduate Employability Needs through Open-source Collaboration with Industry. Proceedings of the 47th ACM Technical Symposium on Computing Science Education. Memphis, Tennessee, USA: ACM. DOI: $10.1145 / 2839509.2844649$

Gordon, N.A. (2010). Group working and peer assessment-using WebPA to encourage student engagement and participation. Innovation in Teaching and Learning in Information and Computer Sciences, 9, 20-31. DOI: 10.11120/ITAL.2010.09010020

Hamilton, M., Carbone, A., Gonsalvez, C. \& Jollands, M. (2015) Breakfast with ICT Employers: What do they want to see in our graduates. Proceedings of the 17th Australasian Computing Education Conference (ACE 2015), 2015. 30.

HESA. (2017). Destinations of Leavers from Higher Education Longitudinal survey

HESA. (2020). What do HE student study? Available online: https://www.hesa.ac.uk/dataand-analysis/students/what-study\#changes [Accessed 25/04/21]

Hribar, M.R. (2005). Sure fire programming: $A$ general framework for independent projects in computer science. Journal of Computing Sciences in Colleges, 21, 257-266.

Joyce, D. \& Elliot, S. (2007) Assessed group work: Staff and student perspectives. 20th Annual Conference of the National Advisory Committee on Computing Qualifications (NACCQ), Nelson, New Zealand, 2007.

Kranov, A.A. \& Khalaf, K. (2016) Investigating the employment gap: What employers want from engineering graduates. IEEE Global Engineering Education Conference (EDUCON), 2016. IEEE, 1198-1201. DOI: 10.1109/EDUCON.2017.7942986

McKinnon, S. \& McCrae, J. (2012). Closing the gap: preparing computing students for employment through embedding work-related learning in the taught curriculum. Industry and Higher Education, 26, 317-322. DOI: 10.5367/IHE.2012.0106

Pastore, F. (2017) Getting it right: youth employment policy within the EU. CESifo Forum. München: ifo Institut-Leibniz-Institut für Wirtschaftsforschung an der Universität München, München, Vol. 18, Iss. 2, pp. 26-33

Patel, N., Brinkman, W.-P. \& Coughlan, J. (2012). Work placements and academic achievement: Undergraduate computing 
students. Education+ Training, 54, 523-533.

DOI: $10.1108 / 00400911211254299$

PRINSLEY, R. T. \& BARANYAI, K. 2013.

STEM skills in the workforce: what do

employers want?, Office of the Chief Scientist.

QAA. (2019a). QAA Subject Benchmark

Statements: Computing. Available online: https://www.qaa.ac.uk/docs/qaa/subjectbenchmark-statements/subject-benchmarkstatement-computing.pdf?sfvrsn=ef2c881_10 [Accessed 25/04/21]

QAA. (2019b). Subject Benchmark

Statements: Computing (Master's). Available online:

https://www.qaa.ac.uk/docs/qaa/subjectbenchmark-statements/subject-benchmarkstatement-computing-

(masters).pdf?sfvrsn=15f2c881_10 [Accessed 25/04/21]

Radermacher, A., Walia, G. \& Knudson, D. (2014) Investigating the skill gap between graduating students and industry expectations. Companion Proceedings of the 36th international conference on software engineering, 2014. ACM, 291-300. DOI: $10.1145 / 2591062.2591159$

Riebe, L., Girardi, A. \& Whitsed, C. (2016). A Systematic Literature Review of Teamwork
Pedagogy in Higher Education, Small Group Research, 47(6), pp. 619-664. DOI: $10.1177 / 1046496416665221$.

Sambell, K., Brown, S. \& Race, P. (2019). Assessment to Support Student Learning: Eight Challenges for 21st Century Practice. AISHE-J: The All Ireland Journal of Teaching and Learning in Higher Education, 11(2).

Thompson, J.B., Edwards, H.M. \& Hardy, C.J. (2005). Providing masters level computing students with real-life learning experiences via capstone projects. Information and Communication Technologies and Real-Life Learning. Springer. DOI: 10.1007/0-38725997-X_26

UNIVERSITIES UK. (2018) Patterns and trends in UK higher education 2018. Available online: https://www.universitiesuk.ac.uk/factsand-stats/data-and-analysis/Pages/Patternsand-trends-in-UK-higher-education-2018.aspx [Accessed 25/04/21].

Wilde, N., White, L.J., Kerr, L.B., Ewing, D.D. \& Krueger, E. (2003) Some experiences with evolution and process-focused projects.

Proceedings 16th Conference on Software Engineering Education and Training, 2003.(CSEE\&T 2003). 2003. IEEE, 242-250. DOI: 10.1109/CSEE.2003.1191383. 